\title{
Mercury Exposure Among Artisanal Gold Miners in Madre de Dios, Peru: A Cross-sectional Study
}

\author{
Ellen E. Yard • Jane Horton • Joshua G. Schier • \\ Kathleen Caldwell • Carlos Sanchez • Lauren Lewis • \\ Carmen Gastaňaga
}

Published online: 28 August 2012

(C) American College of Medical Toxicology (outside the USA) 2012
Results One third (34.0\%) of participants were gold miners. All participants had detectable urine total mercury (GM, $5.5 \mu \mathrm{g} / \mathrm{g}$ creatinine; range, $0.7-151 \mu \mathrm{g} / \mathrm{g}$ creatinine) and $91 \%$ had detectable blood methylmercury (GM, $2.7 \mu \mathrm{g} / \mathrm{L}$; range, $0.6-10 \mu \mathrm{g} / \mathrm{L}) ; 13$ participants $(13 \%)$ reported having kidney dysfunction or a neurological disorder. Urine total mercury concentrations were higher among people who heated gold-mercury amalgams compared with people who never heated amalgams $(p<0.05)$; methylmercury concentrations were higher among fish consumers compared with nonfish consumers $(p<0.05)$.

Conclusion Our findings suggest that mercury exposure may be widespread in Huaypetue.

Keywords Amazon · Mining $\cdot$ Amalgams $\cdot$ Gold · Methylmercury

$\begin{array}{ll}\text { Abbreviations } \\ \text { GM } & \text { Geometric mean } \\ \text { SD } & \text { Standard deviation } \\ \text { LOD } & \text { Limit of detection } \\ \text { CDC } & \text { Centers for Disease Control and Prevention } \\ \text { EPA } & \text { Environmental Protection Agency }\end{array}$

\section{Introduction}

Mercury is a toxic metal that can cause a variety of adverse health effects depending on the form of mercury (elemental, inorganic, or organic) and the pathway, quantity, and duration of exposure. Chronic exposure to small amounts of elemental or inorganic mercury occurs primarily through inhalation of mercury vapors and can cause tremors, kidney dysfunction, and various neurocognitive and behavioral disturbances [1]. Acute exposure to elemental or inorganic mercury can occur in specific occupational settings or during acute poisoning events and can 
result in severe lung injury or death. Chronic exposure to methylmercury, a common type of organic mercury, occurs primarily through eating contaminated fish. It can damage the central nervous system, causing impaired vision and hearing [1]. Methylmercury exposure is of particular concern to the developing fetus who is more susceptible to adverse neurological effects [2].

It is estimated that one tenth of all anthropogenic mercury emissions world-wide are from artisanal gold mining [3]. World-wide, an estimated 10-20 million people mine gold in "artisanal" conditions and an estimated 80-100 million individuals are economically dependent on this way of life [4]. Although artisanal mining operations vary in size, production, and legality, all rely on elemental mercury to extract gold from ore deposits $[4,5]$. To mine gold, large amounts of elemental mercury are mixed with gold ore to form a gold-mercury alloy, called an amalgam. These amalgams contain a mix of mercury and gold; to remove the mercury, they are typically heated in an amalgam furnace. The mercury vaporizes, while the gold stays behind. During this process, mercury is often discarded into the environment. When it enters the water, it can transform into organic mercury compounds, such as methylmercury, and bioaccumulate in fish. This process presents three major potential routes of mercury exposure: (1) miners can have dermal exposure when they mix elemental mercury with gold ore; (2) elemental and inorganic mercury vapors can be inhaled when amalgams are heated; and (3) methylmercury can be consumed from contaminated fish.

Residents of artisanal gold mining communities are at risk for mercury exposure [5]. Previous research found elevated mercury exposure among residents of artisanal mining communities throughout Asia [6, 7], Africa [8, 9], and South America [10-17]. The Peruvian Amazon is a growing hotbed for artisanal mining, and there is growing concern over the extensive environmental mercury contamination that is occurring here [18-20]. One region in particular-Madre de Dios-is estimated to house approximately 30,000 artisanal miners [18]. However, many studies from this region have important laboratory limitations, with many not calculating creatinine-corrected urine mercury concentrations, and most not assessing blood methylmercury. Mercury levels measured in urine best represents exposure to elemental mercury, while mercury levels measured in blood best represents exposure to methylmercury; thus, without both, it is difficult to create a complete picture of mercury exposure.

Thus, our objective was to assess human mercury exposure in Madre de Dios. Specifically, our aims were as follows: (1) to quantify mercury exposure in urine and blood samples among residents of an artisanal mining community in Madre de Dios, (2) to assess risk factors for exposure, and 3) to investigate the relationship between mercury exposure and potential health outcomes.

\section{Methods}

\section{Study Site}

This investigation represented a joint collaboration between the Peru Centro Nacional de Salud Ocupacional y Proteccion del Ambiente para la Salud (CENSOPAS) and the US Centers for Disease Control and Prevention (CDC). Huaypetue, a gold mining town of approximately 7,000 persons, is one of the largest gold mining towns in Madre de Dios and thus was the site chosen for this investigation [21].

\section{Sample Selection}

We conducted a cross-sectional study in Huaypetue in July 2010. Due to the lack of roads, electricity, and security, it was logistically difficult to apply a random selection strategy in Huaypetue. Thus, we nested the mercury assessment in a 3-day health campaign. This health campaign was implemented by the local health directorate and provided free health assessments to all residents. Altogether, 292 residents took part in the health campaign. We invited a convenience sample of 103 of these 292 health campaign attendants $(35.3 \%)$ to participate in the mercury assessment. Inclusion criteria for the mercury assessment were age $\geq 3$ years and residency in Huaypetue $\geq 6$ months. Based on findings from a previous mercury assessment in southern Peru [12], it was determined that this sample size would provide $80 \%$ power to compare differences between exposure groups.

\section{Data Collection}

Participating individuals gave informed consent, provided one spot urine sample and one blood sample, and completed a self-administered questionnaire that collected demographical, dietary, occupational, and health outcome information. The questionnaire contained a standard health assessment form, as well as questions developed specifically for this investigation to assess behaviors and risk factors associated with gold mining and mercury exposure. Most of the questions had categorical responses, as either yes/no, or frequency of a behavior/symptom (daily, weekly, monthly, never). This remained true of the health outcome questions, where participants were asked to respond yes/no to questions such as "Were you ever diagnosed with a kidney 
problem?" Approval was obtained from the Institutional Review Board at the US CDC and the Peru Ministry of Health.

\section{Laboratory Methods}

Spot urine samples (i.e., urine samples collected at random times during the day) and blood samples were collected and aliquoted using equipment certified for trace metal collection. All biological specimens were analyzed at the US CDC's National Center for Environmental Health's Division of Laboratory Sciences in Atlanta, Georgia. Total urine mercury was analyzed using inductively coupled dynamic reaction cell plasma mass spectrometry, which had a limit of detection (LOD) of $0.08 \mu \mathrm{g} / \mathrm{L}$ [22]. Because spot urine samples can vary widely in dilution between persons, all urine samples were adjusted for creatinine concentration to facilitate direct comparisons. Total urine mercury concentration is the best proxy for exposure to elemental mercury, which is oxidized in the body to inorganic mercury and excreted primarily in urine. Whole blood specimens were analyzed for mercury species (inorganic, methyl, and ethyl mercury) using high-performance liquid chromatography. We report blood methylmercury concentration in this paper $(\mathrm{LOD}=0.48 \mu \mathrm{g} / \mathrm{L})$, which is the best proxy for exposure to methylmercury in contaminated fish.

\section{Statistical Analysis}

We used SAS version 9.2 for data analysis. So that they could be included in statistical analyses, mercury concentrations below the LOD were assigned a value equal to the LOD divided by the square root of 2 . We log transformed all urine and blood mercury concentrations; upon visual inspection, the data appeared normally distributed after log transformation. We analyzed urine total mercury and blood methylmercury concentrations descriptively and calculated geometric means (GM) by taking the antilog of the mean of the log-transformed concentrations. We compared GM concentrations between subgroups using $t$ tests for two-level covariates (e.g., sex) and ANOVA for multilevel covariates (e.g., education) and considered $p$ values less than 0.05 to be statistically significant.

We fit separate multivariate linear regression models for each of the two outcomes: (1) log-transformed urine total mercury concentration and (2) log-transformed blood methylmercury concentration. We performed step-wise regression and only included covariates with $p<0.10$ in the final models. We present the exponentiated model coefficients, which can be interpreted as the proportional change in the arithmetic mean associated with each level of the predictor, relative to the referent level, after adjusting for the other predictors in the model. Overall statistical significance of the regression models was assessed via the $F$ test.

\section{Results}

\section{Study Population Characteristics}

We had a $100 \%$ participation rate among the persons invited to participate in the mercury assessment; 103 people $(100 \%)$ completed the questionnaire and provided a blood sample, and $102(99.0 \%)$ provided a urine sample. Participants ranged in age from 3 to 70 years (mean $=33.9$; standard deviation $(\mathrm{SD})=15.8$ ), and slightly over half were male $(53.4 \%)$. Number of years spent living in Huaypetue ranged from 1 to 54 (mean=13.6; $\mathrm{SD}=11.7$ ). Half of all participants obtained their drinking water from the public system $(50.5 \%)$; other common locations were wells $(29.1 \%)$ and springs $(9.7 \%)$. Of those $\geq 18$ years of age, 36 $(41.4 \%)$ had a secondary education and $13(14.9 \%)$ had attended a university.

One third ( $n=35,34.0 \%)$ of participants reported engaging in gold mining activities that placed them in direct contact with mercury at least once a month. This one third was composed of 5 participants $(4.9 \%)$ who mixed mercury with gold ore, 5 participants $(4.9 \%)$ who heated goldmercury amalgams, and 25 participants $(24.3 \%)$ who performed both activities. These 35 individuals ranged in age from 16 to 70 years (mean $=42.0 ; \mathrm{SD}=13.8)$ and were $68 \%$ male. On average, they had mined gold for 10 years (range $=$ $1-40 ; \mathrm{SD}=9.6$ ).

\section{Exposure Biomarkers}

All participants providing a urine sample $(n=102)$ had detectable mercury in their urine, ranging from 0.7 to $151 \mu \mathrm{g} / \mathrm{g}$ creatinine $(\mathrm{GM}=5.5 \mu \mathrm{g} / \mathrm{g}$ creatinine; $\mathrm{SD}=3.4 \mu \mathrm{g} / \mathrm{g}$ creatinine) (Table 1). Urine total mercury concentrations were not statistically different by gender, age, highest education attained, length of time spent residing in Huaypetue, and fish consumption (Table 1). There was also no statistical difference between those who mixed mercury with gold and those who did not mix mercury with gold. However, participants who reported heating gold-mercury amalgams had higher urine total mercury concentrations $(\mathrm{GM}=8.81 \mu \mathrm{g} / \mathrm{g}$ creatinine) compared with those who did not report heating gold-mercury amalgams $(\mathrm{GM}=4.49 \mu \mathrm{g} / \mathrm{g}$ creatinine; $p<0.05)$. This association had a positive linear trend: those who heated amalgams daily had the highest levels (GM= $12.6 \mu \mathrm{g} / \mathrm{g}$ creatinine), followed by those who heated amalgams monthly or weekly (GM=8.05 $\mu \mathrm{g} / \mathrm{g}$ creatinine), followed by those never heating amalgams $(p<0.05)$. There were no associations with the number of years spent mining gold.

Most participants $(n=94,91.3 \%)$ had detectable blood methylmercury concentrations, ranging from 0.6 to $10.0 \mu \mathrm{g} /$ $\mathrm{L}(\mathrm{GM}=2.7 \mu \mathrm{g} / \mathrm{L} ; \mathrm{SD}=2.0 \mu \mathrm{g} / \mathrm{L})($ Table 2$)$. The nine 
Table 1 Creatinine-corrected urine total mercury concentrations (in micrograms per gram creatinine) by sample subgroups, Madre de Dios, Peru, 2010

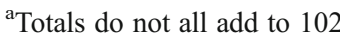
because of missing data

${ }^{\mathrm{b}}$ Only includes participants aged $\geq 18$ years $(n=87)$

${ }^{\mathrm{c}}$ Nonpublic drinking water systems constituted well $(n=30)$, spring $(n=10)$, river $(n=7)$, and water truck $(n=1)$

${ }^{*} p<0.05$ for a $t$ test comparing the geometric means

\begin{tabular}{|c|c|c|c|c|c|c|}
\hline & No. $^{a}$ & Geometric mean & Median & $\begin{array}{l}\text { 75th } \\
\text { percentile }\end{array}$ & $\begin{array}{l}\text { 90th } \\
\text { percentile }\end{array}$ & $\begin{array}{l}\text { 95th } \\
\text { percentile }\end{array}$ \\
\hline Total & 102 & 5.47 & 4.32 & 12.24 & 31.53 & 53.89 \\
\hline \multicolumn{7}{|l|}{ Gender } \\
\hline Male & 55 & 5.74 & 4.39 & 13.12 & 32.81 & 57.72 \\
\hline Female & 46 & 5.19 & 4.25 & 11.43 & 25.05 & 49.77 \\
\hline \multicolumn{7}{|l|}{ Age (years) } \\
\hline $3-21$ & 23 & 4.01 & 2.49 & 7.65 & 15.86 & 17.55 \\
\hline $22-33$ & 27 & 6.16 & 4.39 & 16.31 & 32.96 & 87.39 \\
\hline $34-43$ & 24 & 8.40 & 6.97 & 24.97 & 57.72 & 80.75 \\
\hline $44-70$ & 28 & 4.38 & 3.52 & 8.50 & 24.44 & 31.53 \\
\hline \multicolumn{7}{|c|}{ Highest education attained $^{\mathrm{b}}$} \\
\hline None/some elementary & 38 & 7.26 & 6.59 & 17.57 & 49.77 & 95.09 \\
\hline Secondary & 36 & 4.95 & 3.70 & 8.91 & 32.96 & 80.75 \\
\hline University & 13 & 3.83 & 3.16 & 4.39 & 32.81 & 57.72 \\
\hline \multicolumn{7}{|l|}{ Drinking water source* } \\
\hline Public system & 52 & 4.17 & 3.23 & 6.35 & 18.37 & 49.77 \\
\hline Nonpublic system $^{c}$ & 48 & 7.02 & 5.69 & 17.57 & 48.86 & 87.39 \\
\hline \multicolumn{7}{|c|}{ Mix mercury with gold ore } \\
\hline Yes & 30 & 7.36 & 5.88 & 16.31 & 39.80 & 53.89 \\
\hline No & 72 & 4.84 & 3.94 & 10.47 & 31.53 & 57.72 \\
\hline \multicolumn{7}{|c|}{ Heat gold-mercury amalgams* } \\
\hline Yes & 30 & 8.81 & 8.65 & 18.37 & 51.83 & 87.39 \\
\hline No & 72 & 4.49 & 3.62 & 8.16 & 24.15 & 32.96 \\
\hline \multicolumn{7}{|l|}{ Fish consumption } \\
\hline No & 35 & 5.22 & 4.22 & 11.12 & 31.53 & 87.39 \\
\hline Yes & 50 & 6.04 & 6.11 & 15.86 & 31.32 & 53.89 \\
\hline
\end{tabular}

persons with levels of $\angle \mathrm{LOD}(0.48 \mu \mathrm{g} / \mathrm{L})$ were assigned a level of $0.34 \mu \mathrm{g} / \mathrm{L}$ for remaining analyses. Methylmercury concentration did not statistically differ by mining exposures such as mixing mercury with gold or heating goldmercury amalgams. Methylmercury concentrations were similar among males $(\mathrm{GM}=2.60 \mu \mathrm{g} / \mathrm{L})$ and females $(\mathrm{GM}=$ $1.91 \mu \mathrm{g} / \mathrm{L} ; p=0.09$ ) and among those whose drinking water was from a nonpublic system $(\mathrm{GM}=2.76 \mu \mathrm{g} / \mathrm{L})$ compared with the public system $(\mathrm{GM}=1.95 \mu \mathrm{g} / \mathrm{L})(p=0.05)$. Methylmercury was higher among fish consumers $(\mathrm{GM}=2.58 \mu \mathrm{g} / \mathrm{L})$ compared with nonfish consumers $(\mathrm{GM}=1.61 \mu \mathrm{g} / \mathrm{L}$; $p<0.05)$.

\section{Multivariate Linear Regression}

Two separate multivariate linear regression models were fitone for total urine mercury and one for blood methylmercury (Table 3). For total urine mercury, elevated concentrations were associated with heating amalgams $(p<0.05, F=$ 5.07; $p<0.01$, adjusted $R^{2}=0.08$ ). For blood methylmercury, elevated concentrations were associated with a university level education $(p<0.01)$, obtaining drinking water from a nonpublic system $(p<0.05)$, and consuming fish $(p<0.05)$; those who mixed mercury with gold had decreased methylmercury exposure $(p<0.05, F=4.97 ; p<0.001$, adjusted $\left.R^{2}=0.20\right)$.

\section{Health Outcomes}

Participants were provided with a list of symptoms commonly associated with mercury exposure and asked to report which, if any, they experienced at least once a month. Over half of participants reported experiencing headache (55.4\%), mood swings (52.5\%), and muscle weakness $(51.5 \%)$ (Fig. 1). Those who heated gold-mercury amalgams were more likely to report experiencing memory loss (66.7 vs. $42.2 \%$, respectively; $p<0.05$ ) compared with those who did not heat amalgams.

A few participants reported being previously diagnosed with a medical condition by a health professional (e.g., nurse, doctor, or community health worker). Frequently reported conditions were digestive system disorders $(n=$ 20, $19.4 \%)$, kidney dysfunction ( $n=9,8.7 \%$ ), and nervous system disorders $(n=4,3.9 \%)$. Participants reporting kidney 
Table 2 Blood methylmercury concentrations $(\mu \mathrm{g} / \mathrm{L})$ by sample subgroups, Madre de Dios, Peru, 2010
${ }^{\text {a }}$ Totals do not all add to 103 because of missing data

${ }^{\mathrm{b}}$ Only includes participants aged $\geq 18$ years $(n=87)$

${ }^{\mathrm{c}}$ Nonpublic drinking water systems constituted well $(n=30)$, spring $(n=10)$, river $(n=7)$, and water truck $(n=1)$

${ }^{*} p<0.05$ for a $t$ test comparing the geometric means

\begin{tabular}{|c|c|c|c|c|c|c|}
\hline & No. $^{\mathrm{a}}$ & $\begin{array}{l}\text { Geometric } \\
\text { mean }\end{array}$ & Median & $\begin{array}{l}\text { 75th } \\
\text { percentile }\end{array}$ & $\begin{array}{l}\text { 90th } \\
\text { percentile }\end{array}$ & $\begin{array}{l}\text { 95th } \\
\text { percentile }\end{array}$ \\
\hline Total & 103 & 2.27 & 2.70 & 4.72 & 6.37 & 7.52 \\
\hline \multicolumn{7}{|l|}{ Gender } \\
\hline Male & 55 & 2.60 & 3.26 & 5.07 & 6.37 & 8.99 \\
\hline Female & 46 & 1.91 & 2.01 & 3.80 & 5.33 & 6.41 \\
\hline \multicolumn{7}{|l|}{ Age (years) } \\
\hline $3-21$ & 24 & 2.34 & 2.74 & 4.82 & 6.37 & 7.60 \\
\hline $22-33$ & 27 & 2.09 & 2.52 & 5.23 & 6.78 & 7.52 \\
\hline $34-43$ & 24 & 2.21 & 1.98 & 3.82 & 5.26 & 5.52 \\
\hline $44-70$ & 28 & 2.47 & 3.67 & 4.94 & 6.41 & 6.96 \\
\hline \multicolumn{7}{|c|}{ Highest education attained $^{\mathrm{b}}$} \\
\hline None/some elementary & 38 & 1.81 & 1.73 & 3.89 & 6.39 & 9.86 \\
\hline Secondary & 36 & 2.60 & 3.34 & 5.02 & 5.60 & 6.78 \\
\hline University & 13 & 2.93 & 2.89 & 5.26 & 6.41 & 7.52 \\
\hline \multicolumn{7}{|l|}{ Drinking water source } \\
\hline Public system & 52 & 1.95 & 2.24 & 4.24 & 5.33 & 6.78 \\
\hline Nonpublic system $^{c}$ & 48 & 2.76 & 3.27 & 5.24 & 6.96 & 9.86 \\
\hline \multicolumn{7}{|l|}{ Mix mercury with gold } \\
\hline Yes & 30 & 2.99 & 3.28 & 4.95 & 8.41 & 9.88 \\
\hline No & 73 & 2.03 & 2.52 & 4.59 & 5.52 & 6.41 \\
\hline \multicolumn{7}{|c|}{ Heat mercury-gold amalgams } \\
\hline Yes & 30 & 2.60 & 2.92 & 4.24 & 6.20 & 6.96 \\
\hline No & 73 & 2.15 & 2.65 & 4.72 & 6.37 & 7.60 \\
\hline \multicolumn{7}{|l|}{ Fish consumption* } \\
\hline Yes & 50 & 2.58 & 3.08 & 4.72 & 7.24 & 9.86 \\
\hline No & 35 & 1.61 & 1.58 & 3.26 & 4.94 & 6.37 \\
\hline
\end{tabular}

dysfunction had higher urine total mercury concentrations $(\mathrm{GM}=12.0 \mu \mathrm{g} / \mathrm{g}$ creatinine) than those not reporting kidney dysfunction $(\mathrm{GM}=5.1 \mu \mathrm{g} / \mathrm{g}$ creatinine; $p<0.05)$.

\section{Discussion}

Our findings suggest that mercury exposure may be widespread in Huaypetue. All residents, including nonminers and children, had mercury detected in their urine sample, suggesting recent exposure. Thus, our findings support the need for preventive interventions to reduce mercury exposure in Huaypetue and other artisanal gold mining towns and for continued assessments to measure baseline exposures and evaluate the adoptability and effectiveness of future interventions.

This is one of the first investigations to measure mercury concentrations in an artisanal gold mining community using both urine and blood as biomarkers. Total urine mercury and blood methylmercury represent exposure to different forms of mercury. Total urine mercury concentration primarily represents exposure to the elemental and inorganic forms of mercury that are used to extract gold during the mining process. Conversely, blood methylmercury concentration primarily represents exposure to methylated mercury, which occurs almost exclusively in water-following runoff from mining operations - and thus is most commonly found in contaminated fish [1]. By analyzing mercury levels in both urine and blood, we were able to conduct a more thorough assessment and evaluate various contributing risk factors for exposure.

Similarly to previous studies $[6,8,12,17]$, we found that participants who heated gold-mercury amalgams had elevated urine mercury concentrations compared with those who did not heat amalgams. This corresponds to what is known about mercury uptake in humans; very little elemental mercury is absorbed following dermal contact or ingestion while approximately $80 \%$ of elemental mercury vapors that are inhaled are absorbed [23]. When amalgams are heated, anyone in the vicinity can be exposed to mercury vapors. In Amazonian gold mining communities, amalgam furnaces are often dispersed throughout the town and can be located adjacent to community shops and residences. Thus, anyone who happens to be nearby can be exposed to mercury vapors when amalgams are heated. Given their 
Table 3 Multivariate linear regression models for risk factors of total urine mercury and blood methylmercury exposure, Madre de Dios, Peru, 2010

\begin{tabular}{|c|c|c|c|}
\hline Variable & $\begin{array}{l}\operatorname{Exp}(\beta \\
\text { coefficient) }\end{array}$ & $p$ value & $\begin{array}{l}\text { Adjusted } \\
\text { model } R^{2}\end{array}$ \\
\hline Total urine mercury exposure & & & 0.08 \\
\hline \multicolumn{4}{|l|}{ Drinking water source } \\
\hline Public system & 1.00 & - & \\
\hline Nonpublic system $^{\mathrm{b}}$ & 1.51 & 0.091 & \\
\hline \multicolumn{4}{|l|}{ Heat gold-mercury amalgams } \\
\hline No & 1.00 & - & \\
\hline Yes & 1.85 & 0.030 & \\
\hline Blood methylmercury exposure & & & 0.20 \\
\hline \multicolumn{4}{|l|}{ Highest education attained } \\
\hline None/some elementary & 1.00 & - & \\
\hline Secondary & 1.31 & 0.168 & \\
\hline University & 2.32 & 0.006 & \\
\hline \multicolumn{4}{|l|}{ Drinking water source } \\
\hline Public system & 1.00 & - & \\
\hline Nonpublic system ${ }^{\mathrm{b}}$ & 1.51 & 0.035 & \\
\hline \multicolumn{4}{|l|}{ Mix mercury with gold } \\
\hline No & 1.00 & - & \\
\hline Yes & 0.59 & 0.011 & \\
\hline \multicolumn{4}{|l|}{ Fish consumption } \\
\hline No & 1.00 & - & \\
\hline Yes & 1.61 & 0.012 & \\
\hline
\end{tabular}

${ }^{\text {a }}$ Other drinking water sources constituted well $(n=30)$, spring $(n=10)$, river $(n=7)$, and water truck $(n=1)$

${ }^{\mathrm{b}}$ Nonpublic drinking water systems constituted well $(n=30)$, spring $(n=10)$, river $(n=7)$, and water truck $(n=1)$

potential to disperse mercury vapors throughout a wide area $[12,17]$, it is likely that mercury inhalation via amalgam heating is the primary mercury exposure pathway in most Amazonian artisanal mining communities.

Surprisingly, we found that urine total mercury and blood methylmercury concentrations were elevated in participants who drank water from wells, springs, and other nonpublic systems. In water, elemental mercury is chemically transformed to inorganic and organic forms. Drinking water is not commonly cited as a source of mercury exposure, and $<15 \%$ of ingested inorganic mercury is absorbed by the gastrointestinal tract [1]. It is possible that certain unprotected water sources in this region could contain very high mercury levels, and thus could be a potential exposure pathway. However, it is also possible that this relationship could be a result of confounding by an unmeasured variable.

Our investigation, the first to describe mercury exposure in the Peruvian region of Madre de Dios, found a GM total urine mercury concentration of $5.5 \mu \mathrm{g} / \mathrm{g}$ creatinine. This is an order of magnitude higher than levels documented in the general US population $(0.44 \mu \mathrm{g} / \mathrm{g}$ creatinine) [1], where artisanal mining using mercury is mainly absent. The median urine total mercury concentration measured among miners who reported heating amalgams in our study $(8.65 \mu \mathrm{g} / \mathrm{g}$ creatinine) is in the range found among gold miners in other regions, including Tanzania $(3.55 \mu \mathrm{g} / \mathrm{g}$ creatinine), the Philippines (1.3-7.5 $\mu \mathrm{g} / \mathrm{g}$ creatinine), Indonesia (5.33$10.24 \mu \mathrm{g} / \mathrm{g}$ creatinine), and Zimbabwe (23.4) [6, 8, 11].

Eight study participants had urine total mercury concentrations that exceeded the American Conference of Governmental Industrial Hygienists' recommendation of $35 \mu \mathrm{g} / \mathrm{g}$ creatinine [24], which is a level at which remediation (e.g., removal from high-risk exposures, chemical chelation, etc.) could be considered. These participants were provided their results and offered the opportunity to participate in remediation. However, no participants opted to participate in remediation. Gold mining is the staple economy of the region
Fig. 1 Frequency of symptoms reported by the sample population, stratified by participation in heating amalgams, Madre de Dios, Peru, 2010

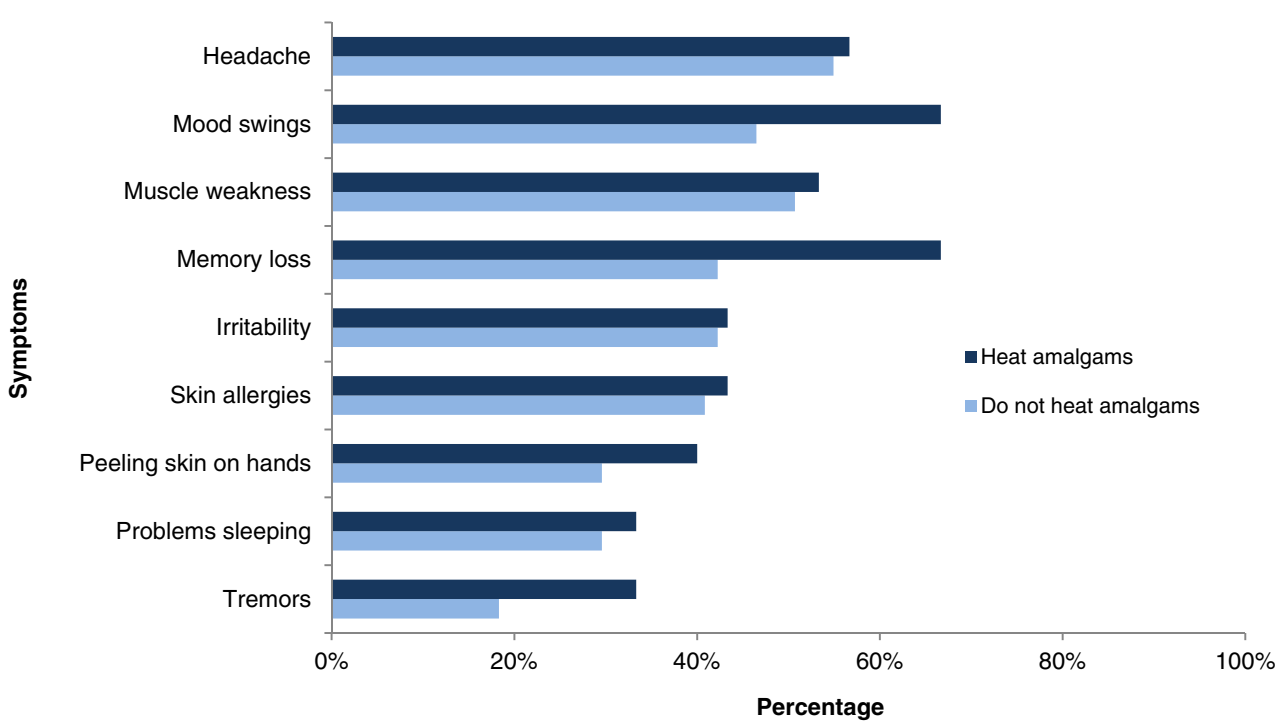


and unfortunately the participants would have been returning to the polluted area postmining. For the remaining participants, urine total mercury levels were below the threshold likely to cause acute poisoning. Insufficient epidemiologic data exist to quantitatively assess the risk of chronic health effects at these lower levels. However, one previous study noted initial nervous system impairment at total urine mercury concentrations as low as $10 \mu \mathrm{g} / \mathrm{g}$ creatinine [25] while another found that persons with total urine mercury concentrations ranging from 30 to $100 \mu \mathrm{g} / \mathrm{g}$ creatinine had initial stages of tremor, psychological disorder, and impaired nervous conduction [26].

In general, methylmercury levels in most of our study participants were below the US Environmental Protection Agency's (EPA) reference dose of $5.8 \mu \mathrm{g} / \mathrm{L}$, which is a level assumed to be without adverse health effects [27]. However, $10.7 \%$ of the total sample population had levels above $5.8 \mu \mathrm{g} /$ L. The potential for harm at these levels is uncertain. Although they are not at risk of acute methylmercury poisoning, these individuals could possibly benefit from reducing their consumption of fish with high mercury levels if other protein sources are readily available. Specifically, the US EPA recommends a maximum daily methylmercury intake of $0.1 \mu \mathrm{g}$ of mercury per kilogram of body weight [27]. This would be particularly important for women of child-bearing age (1649 years), of whom $5.3 \%$ had elevated blood methylmercury levels, because the developing fetus is more susceptible to potential neurological effects [2].

This study had a few limitations. For logistical and safety reasons, we took a convenience sample of people attending a free health campaign. Thus, our results may not be generalizable to all Huaypetue residents. Furthermore, Huaypetue may not be representative of all artisanal mining communities in Madre de Dios. Although blood and urine samples are the gold standard for measuring mercury exposure, they show only recent exposure to mercury during the preceding 1-3 months. The questionnaire was developed as part of a response, and due to the rapid timeframe between instrument development and study implementation, we were unable to assess the questionnaire for validity and reliability. Thus, relationships between risk factor information and mercury exposure should be interpreted cautiously, as some findings were likely biased towards the null. Participants self-reported symptoms, and health outcomes, as there was limited diagnostic capability in the town; thus, these data may not always be reliable. In addition, due to the crosssectional study design, we were unable to determine the timing of symptoms and health outcomes in relation to exposure. Finally, this study did not measure pathways of exposure and did not capture the time of last occupational use of mercury prior to sample collection.

This investigation also had several strengths. We drew a demographically diverse sample from a remote location that is often inaccessible to researchers, and we had a $100 \%$ participation rate. We collected urine and blood samples in a controlled area, away from the center of town where amalgam heating takes place, and thus there was limited potential for environmental contamination of urine samples. Finally, we collected information on a large number of risk factors.

This investigation supports the need for mitigation efforts to decrease mercury exposure in artisanal mining communities. These efforts might include warning community members about the risk of adverse health effects from mercury exposure and encouraging the adoption of mining practices that utilize less mercury. Specifically, creating centralized amalgamation centers located away from commercial and residential areas and facilitating the installation and use of amalgam furnace retorts to decrease emissions are recommended. Because artisanal mining communities lack an organized governmental structure, educating disparate groups of miners and implementing safer practices will require a unified, persistent effort. Increasing public awareness of this health threat is needed to encourage governments, public health agencies, nonprofit organizations, and individual miners to invest in this issue.

Acknowledgments We thank the Peru National Center for Occupational Health and Environmental Protection, the Madre de Dios Health Department, and the Huaypetue Clinic for carrying out the Madre de Dios health campaign. Specifically, we thank John Astete for his hard work.

Funding This study was supported by the US CDC National Center for Environmental Health.

Competing Interests The contents of this paper are solely the responsibility of the authors and do not represent the official views of the CDC. The authors declare they have no competing financial interests.

\section{References}

1. Centers for Disease Control and Prevention, (2009) Fourth National Report on Human Exposure to Environmental Chemicals. Available at: http://www.cdc.gov/exposurereport/

2. Gilbert SG, Grant-Webster KS (1995) Neurobehavioral effects of developmental methylmercury exposure. Environ Health Perspect 103(Suppl 6): 135-142

3. Telmer K, Veiga M (2009) World emissions of mercury from small scale and artisanal gold mining, in mercury fate and transport in the global atmosphere. In: Pirrone N, Mason R (eds) Emissions, measurements and models. Springer, New York, pp 131-172

4. International Labour Organization (1999), Social and Labour Issues in Small-Scale Mines. Geneva. Available at: http://www. ilo.org/public/english/dialogue/sector/techmeet/tmssm99/ tmssmr.htm.

5. Veiga, M (1997) Mercury in Artisanal Gold Mining in Latin America: facts, fantasies, and solutions, UNIDO, Expert Group Meeting, Vienna, Austria, 1-3 Jul

6. Bose-O'Reilly S et al (2010) Health assessment of artisanal gold miners in Indonesia. Sci Total Environ 408(4):713-725 
7. Drasch G et al (2001) The Mt. Diwata study on the Philippines 1999 - assessing mercury intoxication of the population by small scale gold mining. Sci Total Environ 267(1-3):151-168

8. Bose-O'Reilly S et al (2010) Health assessment of artisanal gold miners in Tanzania. Sci Total Environ 408(4):796-805

9. Odumo OB et al (2011) Multielemental analysis of Migori (Southwest, Kenya) artisanal gold mine ores and sediments by EDX-ray fluorescence technique: implications of occupational exposure and environmental impact. Bull Environ Contam Toxicol 86(5):484-489

10. Ashe K (2012) Elevated mercury concentrations in humans of Madre de Dios, Peru. PLoS One 7(3):e33305

11. Bose-O'Reilly S et al (2008) Mercury as a serious health hazard for children in gold mining areas. Environ Res 107(1):89-97

12. Hurtado J, Gonzales GF, Steenland K (2006) Mercury exposures in informal gold miners and relatives in southern Peru. Int J Occup Environ Health 12(4):340-345

13. Counter SA, Buchanan LH, Ortega F (2005) Mercury levels in urine and hair of children in an Andean gold-mining settlement. Int J Occup Environ Health 11(2):132-137

14. Palheta D, Taylor A (1995) Mercury in environmental and biological samples from a gold mining area in the Amazon region of Brazil. Sci Total Environ 168(1):63-69

15. Pinheiro MC et al (2006) Comparative study of human exposure to mercury in riverside communities in the Amazon region. Braz J Med Biol Res 39(3):411-414

16. de Jesus IM et al (2001) Exposure to elemental mercury in urban workers and gold miners from the Tapajos Region, Para, Brazil. Bull Environ Contam Toxicol 67(3):317-323
17. Drake PL et al (2001) Occupational exposure to airborne mercury during gold mining operations near El Callao, Venezuela. Int Arch Occup Environ Health 74(3):206-212

18. Fraser B (2009) Peruvian gold rush threatens health and the environment. Environ Sci Technol 43(19):7162-7164

19. BBC News, (2009) Peru's gold rush sparks fears of ecological disaster. BBC News

20. Swenson JJ et al (2011) Gold mining in the Peruvian Amazon: global prices, deforestation, and mercury imports. PLoS One 6(4): e18875

21. Peru National Institute of Statistics and Information, (2007) National Census. Available at: http://desa.inei.gob.pe/censos2007/ tabulados/

22. Caldwell KL et al (2005) Inductively coupled plasma mass spectrometry to measure multiple toxic elements in urine in NHANES 1999-2000. Atomic Spectroscopy 26(1):1-7

23. World Health Organization, (2000) WHO air quality guidelines for Europe, 2nd edition, p. Chapter 6.9

24. ACGIH, (2003) TLVs ${ }^{\circledR}$ and BEIs ${ }^{\circledR}$ : threshold limit values for chemical substances and physical agents and biological exposure indices. In: American Conference of Governmental Industrial Hygienists, Cincinnati $(\mathrm{OH})$.

25. Lucchini R et al (2002) Neurotoxic effect of exposure to low doses of mercury. Med Lav 93(3):202-214

26. Kazantzis G (2002) Mercury exposure and early effects: an overview. Med Lav 93(3):139-147

27. Environmental Protection Agency, (2010) Mercury: human exposure. Available at: http://www.epa.gov/hg/exposure.htm 